\title{
Uptake of pyrimidines and their derivatives into Candida glabrata and Candida albicans
}

\author{
M. O. F. FASOLI and D. KERRIDGE* \\ Department of Biochemistry, Tennis Court Road, Cambridge CB2 1QW, UK
}

(Received 29 January 1990; revised 2 March 1990; accepted 2 April 1990)

\begin{abstract}
The uptake of pyrimidines and their derivatives into Candida glabrata and Candida albicans was measured using a novel technique in which the cells were rapidly separated from their suspending medium by centrifugation through a layer of an inert oil. The uptake of $\mathbf{1}^{14} \mathrm{C} \mid c y$ tosine was linear for $30 \mathrm{~s}$ for all concentrations of pyrimidine tested. In $C$. glabrata but not $C$. albicans cytosine transport was mediated by both a high affinity $\left(K_{\mathrm{m}} 0 \cdot 8 \pm 0 \cdot 1 \mu \mathrm{M}\right)$, low capacity $\left[V 40 \pm 4 \mathrm{pmol}(\mu \mathrm{l} \text { cell water })^{-1} \mathrm{~s}^{-1}\right]$ and a low affinity $\left[K_{\mathrm{m}} 240 \pm 35 \mu \mathrm{M}\right]$, high capacity system $[V 770 \pm$ $170 \mathrm{pmol}\left(\mu \mathrm{l}\right.$ cell water) $\left.{ }^{-1} \mathrm{~s}^{-1}\right]$. The cytosine permease in $C$. glabrata was specific for cytosine and 5 fluorocytosine. In $C$. albicans there was only one cytosine transport system $\left[K_{\mathrm{m}} 2 \cdot 4 \pm 0 \cdot 3 \mu \mathrm{M} ; V 50 \pm 4 \mathrm{pmol}(\mu l\right.$ cell water) ${ }^{-1} \mathbf{s}^{-1}$; this system also transported adenine, guanine and hypoxanthine. Differences in nucleoside transport were also observed for $C$. glabrata and $C$. albicans, with the uridine permease in $C$. glabrata transporting only uridine and 5-fluorouridine whereas cytidine and adenosine were also transported by the uridine permease in $C$. albicans. Studies on the effect of nucleoside analogues on uridine transport in $C$. glabrata demonstrated the importance of the sugar moiety in determining the specificity of transport, with a hydroxyl residue on $\mathrm{C}-2$ being apparently essential for transport.
\end{abstract}

\section{Introduction}

The uptake of a nutrient into cells consists in most cases of two events operating in tandem; an initial transport of the nutrient across the plasma membrane followed by its intracellular metabolism. The study of nutrient transport requires a compartmentalized system and a method of uncoupling transport from further metabolism of the substrate. This uncoupling can be genetic, kinetic or by chemical manipulation. Another key element is the rapidity with which cells and suspending medium can be separated. Most studies of the transport of purines, pyrimidines and their nucleosides into yeasts have involved measuring uptake of radioactively labelled substrates after a short incubation period during which time uptake was linear, and then separating the cells from the medium by filtration. In Saccharomyces cerevisiae and Candida albicans such studies have demonstrated that uptake of purines and pyrimidines is linear for $30 \mathrm{~s}$ but give no indication if this is true for all concentrations used to determine the kinetic parameters

Abbreviations: 5-FC, 5-fluorocytosine; 5-FU, 5-fluorouracil; 5-FUrd, 5-fluorouridine; 5-FdUrd, 5-fluoro-2-deoxyuridine; YNBG, Yeast Nitrogen Base + glucose; YMA, Yeast Morphology Agar.
(Chevallier et al., 1975; Jund et al., 1977; Rao et al., 1983). This technique is limited if the initial linear phase of substrate transport is very short as is the case with pyrimidine transport into mammalian cells (Wohlhueter et al., 1978). Another limitation of the filtration procedure is the risk of loss of the intracellular substrate from organisms where metabolism is uncoupled from transport or a non-metabolizable substrate used.

A technique used to overcome the limitations imposed by filtration and washing involves separating the cells from the suspending medium by centrifugation through a layer of an inert oil. This ensures a rapid separation of the cells from the substrate and also obviates the requirement for washing the cells so eliminating the possibility of removing any intracellular substrate (Wohlhueter et al., 1978). Centrifugation through oil was originally developed to measure substrate transport into animal cells and has been adapted in the studies reported here to investigate the transport of pyrimidines, purines and their nucleosides into Candida spp. Purine and pyrimidine permeases have been studied in both $S$. cerevisiae and $C$. albicans using the filtration procedure. There are a number of permeases involved which show different degrees of specificity, with cytosine, adenine, guanine and hypoxanthine being transported by a single per- 
mease (Polak \& Grenson, 1973). The transport of purines and pyrimidines into yeast is energy coupled involving an electrogenic symport; however, the stoichiometry appears to differ for cytosine and uracil (Hopkins et al., 1988).

We have undertaken a study of the specificity and enzyme kinetics of nucleobase and nucleoside transport in the haploid yeast $C$. glabrata using a rapid sampling centrifugation procedure and extended these studies to re-evaluate uptake into $C$. albicans.

\section{Methods}

Organisms and preparation of cell suspensions. The organisms used in these experiments were $C$. glabrata strain 4 (Whelan et al., 1984), $C$. albicans strain $72 \mathrm{~S}$ (Whelan \& Kerridge, 1984) and fluoropyrimidineresistant strains derived from them (Fasoli \& Kerridge, 1988). Details of these strains are given in Table 1. For uptake experiments cultures were grown aerobically at $37^{\circ} \mathrm{C}$ in Yeast Nitrogen Base (Difco) supplemented with $1 \%(\mathrm{w} / \mathrm{v})$ glucose (YNBG) to mid-exponential phase. Under these conditions $C$. albicans grew in the yeast form. After harvesting by centrifugation and washing twice in deionized water, the cells were resuspended in sodium citrate buffer (50 mM; pH 5.4) containing $2 \%(\mathrm{w} / \mathrm{v})$ glucose to a final density of $5 \times 10^{7}$ cells $\mathrm{ml}^{-1}$, as determined by haemocytometer count. The cell suspensions were shaken at 190 r.p.m. for $1 \mathrm{~h}$ at room temperature $\left(21^{\circ} \mathrm{C}\right)$, harvested by centrifugation and resuspended to the same density in fresh buffer containing glucose. This cell suspension was maintained at room temperature and used within $60 \mathrm{~min}$ of preparation for transport studies.

Determination of the growth inhibitory effects of nucleoside analogues on Candida spp. Cells of both parental and uridine-permease-deficient strains of C. albicans and C. glabrata which had been grown at $37^{\circ} \mathrm{C}$ for $24 \mathrm{~h}$ on Yeast Morphology Agar (Difco) (YMA) were suspended in saline $(0.85 \% \mathrm{NaCl})$ and approximately $10^{6}$ cells spread onto $20 \mathrm{ml}$ fresh YMA in a Petri dish. A paper disc containing $100 \mu \mathrm{g}$ of the analogue was placed in the centre of the agar and after $48 \mathrm{~h}$ incubation at $37{ }^{\circ} \mathrm{C}$, the agar plate was inspected for the presence of a zone of growth inhibition around the disc. For each analogue a control disc containing the solvent used to dissolve the analogue was also tested.

Determination of the effects of nucleosides on 5-fluorouridine toxicity to Candida spp. Overnight cultures of yeast grown in YNBG at $37^{\circ} \mathrm{C}$ with shaking were used to inoculate YNBG $(5 \mathrm{ml})$ containing 5-fluorouridine (5-FUrd) at three concentrations $(5,50$ or $500 \mu \mathrm{M})$ together with the required nucleoside (uridine, thymidine or adenosine) at $1000 \mu \mathrm{M}$. After $24 \mathrm{~h}$ at $37^{\circ} \mathrm{C}$, growth was measured as the optical density at 600 $\mathrm{nm}$ and compared with that of control cultures grown in the absence of 5-FUrd.

Permease assay. A variation of the method described by Harley et al. (1982) was employed. Cell suspensions $(100 \mu \mathrm{l})$ were layered over $150 \mu \mathrm{l}$ inert oil (dibutyl phthalate/dinonylphthalate, 55:45, v/v; specific gravity $1.01 \mathrm{~g} \mathrm{ml}^{-1}$ ) in $12 \times 1.5 \mathrm{ml}$ Eppendorf microcentrifuge tubes; the tubes were placed in an Eppendorf Microfuge (model 5414) with a 12-place fixed-angle rotor. Uptake of pyrimidines or their derivatives was initiated by the rapid addition of $100 \mu$ liquots of radioactively labelled substrate in citrate buffer, $\mathrm{pH} 5 \cdot 4$, to each tube at $2 \mathrm{~s}$ intervals. Additions were done with a calibrated, repetitive pipette (Eppendorf Multipette 4780). Uptake was terminated by switching the centrifuge on $2 \mathrm{~s}$ after the addition of the reaction mixture to the last tube, and centrifuging at full speed for $30 \mathrm{~s}$. After centrifugation, the supernatant fluid was aspirated with a syringe and $2 \times 1 \mathrm{ml}$ water added above the oil phase and then aspirated to remove any remaining radioactivity. The oil layer was removed with the last wash and the bottoms of the tubes (containing the pellets) were cut off with a razor blade and placed in plastic scintillation vials. Triton X-100 $(2 \%, w / v)(150 \mu l)$ was added and the vials were vortexed to resuspend the pellets. Optiphase Safe scintillant $(2 \mathrm{ml})$ was added to the vials, and after thorough mixing to dissolve the contents, the radioactivity was assayed in a Beckman LS3801 scintillation counter.

Formulation of the oil phase was arrived at empirically by testing several types of oil and mixtures. The criterion used was the presence of a firm cell pellet after 30 s centrifugation; this was checked by visual examination of the pellet and by microscopical examination for the absence of cells at the oil/aqueous solution interface. Non-specific binding of radioactivity to the surface of cells was measured using aliquots of cell suspensions which had been heated in a boiling bath for $2 \mathrm{~min}$. The controls were run in duplicate for every concentration of substrate tested. Non-specific binding of radioactivity to cells was negligible for all compounds studied with the exception of uridine, where it represented $10-15 \%$ of the intracellular radioactivity.

Fractionation of radioactively labelled material in the low molecular mass intracellular pool. Metabolism was stopped by centrifuging the cells through an oil layer into $50 \mu 10.2 \mathrm{M}$-TCA in $10 \%(\mathrm{w} / \mathrm{v})$ sucrose (density $1.04 \mathrm{~g} \mathrm{ml}^{-1}$ ) placed beneath the oil. Following centrifugation and a water wash, the cell pellets were extracted with $1 \mathrm{ml}$ ice-cold diethyl ether to remove any residual oil and most of the TCA. Fractionation into free bases, nucleosides and nucleotides was then done as previously described (Wohlhueter et al., 1978).

Table 1. Characteristics of the fluoropyrimidine-resistant organisms used

\begin{tabular}{|c|c|c|c|c|}
\hline Candida sp. & Strain & $\begin{array}{l}\text { Parent } \\
\text { strain }\end{array}$ & Phenotype* & Lesion \\
\hline Candida glabrata & $\begin{array}{l}4 \\
\text { cp1 } \\
\text { up1 } \\
\text { udp1 } \\
\text { udp2 } \\
\text { cd3 } \\
\text { upy0 }\end{array}$ & $\begin{array}{l}4 \\
4 \\
4 \\
4 \\
4 \\
4\end{array}$ & 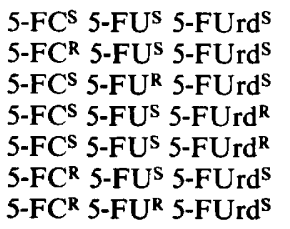 & \begin{tabular}{l}
\multicolumn{1}{c}{-} \\
Cytosine permease \\
Uracil permease \\
Uridine permease \\
Uridine permease \\
Cytosine deaminase \\
UMP:pyrophosphorylase
\end{tabular} \\
\hline Candida albicans & $\begin{array}{l}72 \mathrm{~S} \\
6 \mathrm{~F} 1\end{array}$ & $72 S$ & $\begin{array}{l}\text { 5-FCS } 5-\mathrm{FU}^{\mathrm{S}} 5 \text {-FUrd } \mathrm{F}^{\mathrm{S}} \\
\text { 5-FCS } 5-\mathrm{FU}^{\mathrm{S}} 5 \text {-FUrd }\end{array}$ & Uridine permease \\
\hline
\end{tabular}

* 5-FC, 5-fluorocytosine; 5-FU, 5-fluorouracil; 5-FUrd, 5-fluorouridine. 
Estimation of intracellular and extracellular space in C. albicans and $C$. glabrata. A solution containing $5 \mu \mathrm{Ci}(185 \mathrm{kBq})\left[\right.$ carboxyl $\left.-{ }^{14} \mathrm{C}\right]$ inulin and $10 \mu \mathrm{Ci}(370 \mathrm{kBq}){ }^{3} \mathrm{H}_{2} \mathrm{O}$ per ml of citrate buffer was mixed with an equal volume of the cell suspension. Triplicate samples $(200 \mu \mathrm{l})$ were removed after $2 \mathrm{~min}$ and carefully layered above $100 \mu$ lof oil in $1.5 \mathrm{ml}$ Eppendorf microcentrifuge tubes. Centrifugation and sample preparation were done as for the transport experiments. ${ }^{3} \mathrm{H}$ and ${ }^{14} \mathrm{C}$ were assayed using an internally standardized, dual channel Beckman LS3801 scintillation counter. The intracellular water space was calculated by difference. The data were evaluated assuming that: (i) [carboxyl-14 C]inulin $\left(M_{\mathrm{r}} 5200\right)$ was distributed evenly throughout the extracellular space (outside the cell wall) (Scherrer et al., 1974); (ii) ${ }^{3} \mathrm{H}_{2} \mathrm{O}$ was distributed evenly throughout the total water space in the cell pellet; and (iii) the space between cell wall and plasma membrane is negligible relative to the intracellular space (Arnold, 1973).

The water space of pellets of all strains of $C$. glabrata used was $2.63 \pm 0.19 \mu \mathrm{l}$ per $10^{8}$ cells (mean $\pm \mathrm{SD}$ ). The comparable result for $C$. albicans strain $72 \mathrm{~S}$ was $3.45 \pm 0.27 \mu \mathrm{l}$ per $10^{8}$ cells.

Sources of chemicals. 5-Fluoro $\left.{ }^{14} \mathrm{C}\right]$ cytosine (5-FC) was a gift from $\mathrm{Dr}$ A. Polak, Hoffman-La Roche. $\left[{ }^{14} \mathrm{C}\right]$ Cytosine was obtained from CEA. All other radioactively labelled compounds were obtained from Amersham. Nucleobases, nucleosides, nucleotides and their analogues were obtained from Sigma.

\section{Results and Discussion}

Characterization of pyrimidine transport into C. glabrata and C. albicans.

Studies on the uptake of nutrients into Candida spp. provided strong evidence that filtration is an inadequate method for the accurate measurement of the kinetic parameters of substrate transport in yeast (Fasoli, 1989).

Measurements of the rate of transport of pyrimidines in both $C$. glabrata and $C$. albicans by the oilcentrifugation technique as a function of cell density indicated that this parameter was reproducible and remained constant over a range of cell densities from $3.3 \times 10^{6}-3.3 \times 10^{8}$ cells $\mathrm{ml}^{-1}$. The experiments were done at $21{ }^{\circ} \mathrm{C}$ rather than the growth temperature of $37^{\circ} \mathrm{C}$; this would have had the effect of reducing the maximum rate of uptake. These results coupled with the absence of non-specific binding confirmed the suitability of this method for separating cells from the suspending medium when measuring transport of radiolabelled substrates into yeast.

The uptake of cytosine, thymine and uracil into both C. glabrata strain 4 and C. albicans strain $72 \mathrm{~S}$ was linear for 30-60 $\mathrm{s}$ at all concentrations of pyrimidine examined from $1 \mu \mathrm{M}-1000 \mu \mathrm{M}$. The curves did not extrapolate to zero radioactivity at zero time since no account was taken of the time lag between starting the centrifuge and effective sedimentation of the cells through the oil layer. This time lag was $2.5 \pm 0.2 \mathrm{~s}$ (mean of 12 time courses in duplicate \pm SD). In all experiments nominal sampling times were increased by $2.5 \mathrm{~s}$ for the purpose of calculating the initial rates of uptake. During the first
45 s of incubation of both C. albicans and C. glabrata with a radioactively labelled pyrimidine (cytosine, uracil and thymine) or pyrimidine nucleoside (cytidine, uridine and thymidine) less than $15 \%$ of the total radioactivity could be detected in the pyrimidine nucleotide fraction. In all determinations of the kinetic parameters of pyrimidine transport the uptake of substrate after $30 \mathrm{~s}$ was used as a measure of the initial rate.

Incorporation of cytosine was followed in C. glabrata strain 4 over a longer time period $(6 \mathrm{~min})$ to determine both the nature of the accumulated radioactivity and the time taken to reach steady-state levels of free intracellular pyrimidine. By $200-300 \mathrm{~s}$ the concentration of cytosine in the intracellular pool had achieved a steadystate value $(6 \mathrm{mM})$; the increase in total radioactivity from this time onwards measured solely the combined rates of deamination of cytosine and the subsequent phosphorylation of uracil. Chromatographic analysis of the intracellular accumulated products in both $C$. albicans and $C$. glabrata, following their exposure to all the pyrimidines tested, indicated that the incorporated radioactivity could be recovered predominantly as the free base after the first 30-60 s. After this time there was a significant decrease in the percentage of radioactivity recovered as the free base and a simultaneous increase in the level of phosphorylated derivatives. This supports the concept that the initial transport of pyrimidines into the cell is functionally separate from their subsequent phosphorylation.

Initial velocities of transport of $\left[{ }^{14} \mathrm{C}\right]$ cytosine into $C$. glabrata strain 4 were determined as a function of external cytosine concentration after a single $30 \mathrm{~s}$ incubation by the oil-centrifugation assay. The results obtained were analysed graphically by a LineweaverBurk plot (Fig. 1); this demonstrated the existence of two kinetic functions, corresponding to a high affinity, low capacity system, and a low affinity, high capacity system. The apparent affinities ( $K_{\mathrm{m}}$ values) were $0.8 \mu \mathrm{M}$ and $240 \mu \mathrm{M}$ respectively (Table 2 ). These results contrasted with those for $C$. albicans strain $72 \mathrm{~S}$, where cytosine transport was a single phase system with $K_{\mathrm{m}}$ of $2 \cdot 4 \mu \mathrm{M}$ (Table 3).

Studies on the effect of substrate concentration on the accumulation of other radioactively labelled pyrimidines and their nucleoside derivatives indicated that in both C. glabrata strain 4 and $C$. albicans strain $72 S$ these substances are also transported into the cell by saturable systems displaying simple Michaelis-Menten kinetics (Tables 2 and 3). The experimentally determined $K_{\mathrm{m}}$ and $V$ values differed for all pyrimidines analysed except for cytosine and 5-FC which utilize the same permease to enter the cell. In C. glabrata, the cytosine permease had the highest affinity for its substrate $\left(K_{\mathrm{m}} 0.8 \mu \mathrm{M}\right.$ at low concentrations) and the thymine permease the lowest 


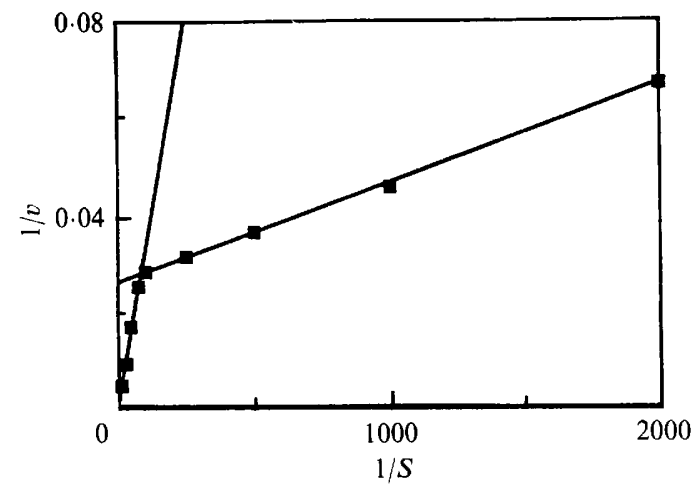

Fig. 1. Cytosine uptake by $C$. glabrata strain 4 . Initial velocities of uptake $\left.[v ; \text { pmol ( } \mu \mathrm{l} \text { intracellular water })^{-1} \mathbf{s}^{-1}\right]$ of cytosine as a function of external concentration $(S ; \mathrm{mm})$ were measured in $30 \mathrm{~s}$ assays as described in the text; the results are plotted according to LineweaverBurk.
$\left(K_{\mathrm{m}} 110 \mu \mathrm{M}\right)$. The low affinity transport system for cytosine had the highest maximum velocity $[770 \mathrm{pmol}(\mu \mathrm{l}$ cell water) ${ }^{-1} \mathrm{~s}^{-1}$ ] whereas that of cytidine the lowest $\left[8.8 \mathrm{pmol}(\mu \mathrm{l} \text { cell water })^{-1} \mathrm{~s}^{-1}\right]$. In $C$. albicans, the cytosine permease had the highest affinity for its substrate $\left(K_{\mathrm{m}} 2 \cdot 4 \mu \mathrm{M}\right)$ and that for thymine the lowest $\left(K_{\mathrm{m}}\right.$ $124 \mu \mathrm{M})$. Cytosine transport had the highest maximum velocity $\left[49.8 \mathrm{pmol}(\mu \mathrm{l} \text { cell water })^{-1} \mathrm{~s}^{-1}\right]$ and uracil the lowest $\left[7.2\right.$ pmol $\left.(\mu \text { l cell water })^{-1} \mathrm{~s}^{-1}\right]$.

The transport of pyrimidines was measured in strains of Candida where the transport step was uncoupled from any further metabolism of the substrate once inside the cell by virtue of the loss of an enzyme of the pyrimidine salvage pathway. The $K_{\mathrm{m}}$ and $V$ values for the transport of cytosine into strains either deficient for cytosine deaminase or UMP pyrophosphorylase, or for uracil-

Table 2. Characteristics of pyrimidine and pyrimidine nucleoside transport in C. glabrata

The steady-state intracellular concentration of substrate $\left(S_{\mathrm{i}}\right)$ was determined after $5 \mathrm{~min}$ incubation with radioactively labelled pyrimidine or pyrimidine nucleoside $\left[50 \mu \mathrm{M} ; 10 \mu \mathrm{Ci} \mathrm{ml}^{-1}\right.$ $\left(370 \mathrm{kBq} \mathrm{ml}^{-1}\right)$ ]. Cells were centrifuged through an oil layer and radioactivity in the soluble pyrimidine pool and the supernatant fluid, which corresponded to the pyrimidine initially in the medium, was measured. $K_{\mathrm{m}}$ and $V$ values were calculated from weighted, best line fits of Lineweaver-Burk plots. All values were determined with wild-type strain 4 except for cytosine, where $S_{\mathrm{i}}$ and $S_{\mathrm{i}} / S_{0}$ values were determined for $C$. glabrata strain cd3 (cytosine-deaminasedeficient), as a significant amount of intracellular radioactivity was present in the form of uracil and nucleotides after $5 \mathrm{~min}$ incubation with $\left[{ }^{14} \mathrm{C}\right]$ cytosine. There were no differences between $K_{\mathrm{m}}$ and $V$ values for pyrimidine transport into strain cd 3 and the parental strain 4 (Table 4). $S_{0}$, substrate (radioactivity) concentration outside cell.

\begin{tabular}{|c|c|c|c|c|}
\hline Substrate & $S_{\mathrm{i}}(\mu \mathrm{M})$ & $S_{\mathrm{i}} / S_{0}$ & $\begin{array}{l}K_{\mathrm{m}}(\mu \mathrm{M}) \\
\pm \mathrm{SD}\end{array}$ & $\begin{array}{c}V\left[\mathrm{pmol}(\mu \mathrm{l} \text { cell water })^{-1} \mathrm{~s}^{-1}\right] \\
\pm \mathrm{SD}\end{array}$ \\
\hline Cytosine & 6100 & 120 & $\begin{array}{ll}\text { high aff.: } & 0 \cdot 8 \pm 0 \cdot 1 \\
\text { low aff.: } & 240 \pm 35\end{array}$ & $\begin{array}{c}39 \cdot 7 \pm 3 \cdot 2 \\
770 \pm 170\end{array}$ \\
\hline Uracil & 180 & 3.6 & $13.6 \pm 1.5$ & $23.6 \pm 2.7$ \\
\hline Thymine & 200 & $4 \cdot 4$ & $100 \pm 23$ & $14 \cdot 8 \pm 2 \cdot 0$ \\
\hline Cytidine & 260 & $5 \cdot 1$ & $87.5 \pm 9.3$ & $8.8 \pm 1.9$ \\
\hline Uridine & 1100 & 22 & $17 \cdot 7 \pm 2 \cdot 1$ & $18.8 \pm 2.6$ \\
\hline Thymidine & 290 & $5 \cdot 8$ & $83.1 \pm 9.5$ & $10 \cdot 2 \pm 1 \cdot 1$ \\
\hline 5-Fluorocytosine & 5800 & 115 & $\begin{array}{l}\text { high aff.: } 1 \cdot 1 \pm 0 \cdot 2 \\
\text { low aff.: } 224 \pm 31\end{array}$ & $\begin{array}{l}36.6 \pm 3.9 \\
705 \pm 163\end{array}$ \\
\hline
\end{tabular}

Table 3. Characteristics of pyrimidine and pyrimidine nucleoside transport in C. albicans

The steady-state intracellular concentration of substrate $\left(S_{\mathrm{i}}\right)$ was determined after $5 \mathrm{~min}$ incubation with radioactively labelled pyrimidine $\left[50 \mu \mathrm{M} ; 10 \mu \mathrm{Ci} \mathrm{ml} l^{-1}\left(370 \mathrm{kBq} \mathrm{ml}{ }^{-1}\right)\right]$. Cells were centrifuged through oil and the radioactivity in the soluble pool and the supernatant fluid, which corresponded to the pyrimidine or pyrimidine nucleoside in the medium, was measured. $K_{\mathrm{m}}$ and $V$ values were calculated from weighted, best line fits of Lineweaver-Burk plots.

\begin{tabular}{|c|c|c|c|c|}
\hline Substrate & $S_{\mathrm{i}}(\mu \mathrm{M})$ & $S_{\mathrm{i}} / S_{0}$ & $\begin{array}{l}K_{\mathrm{m}}(\mu \mathrm{M}) \\
\quad \pm \mathrm{SD}\end{array}$ & $\begin{array}{c}V\left[\mathrm{pmol}(\mu \mathrm{l} \text { cell water })^{-1} \mathrm{~s}^{-1}\right] \\
\pm \mathrm{SD}\end{array}$ \\
\hline Cytosine & 5300 & 106 & $2 \cdot 4 \pm 0.3$ & $49 \cdot 8 \pm 4 \cdot 2$ \\
\hline Uracil & 200 & $4 \cdot 4$ & $114 \pm 15$ & $7.2 \pm 0.9$ \\
\hline Thymine & 430 & $8 \cdot 6$ & $124 \pm 22$ & $25.9 \pm 3.1$ \\
\hline Cytidine & 340 & $6 \cdot 8$ & $106 \pm 11$ & $8.3 \pm 0.9$ \\
\hline Uridine & 1400 & 28 & $17 \cdot 7 \pm 2 \cdot 1$ & $34.7 \pm 3.8$ \\
\hline Thymidine & 370 & $7 \cdot 4$ & $76.5 \pm 7.9$ & $20 \cdot 2 \pm 2 \cdot 0$ \\
\hline 5-Fluorocytosine & 4900 & 98 & $2.7 \pm 0.3$ & $49.9 \pm 5.5$ \\
\hline
\end{tabular}


Table 4. Characteristics of cytosine and uracil transport in C. glabrata strain 4 and mutant strains

$K_{\mathrm{m}}$ and $V$ values were calculated from weighted, best line fits of Lineweaver-Burk plots, following transport assays as described in Methods. ND, no pyrimidine uptake detected after $30 \mathrm{~s}$ incubation, using a specific radioactivity of $5 \mu \mathrm{Ci} \mu \mathrm{mol}^{-1}\left(185 \mathrm{kBq} \mu \mathrm{mol}^{-1}\right)$ and pyrimidine concentrations up to $1 \mathrm{~mm}$.

\begin{tabular}{|c|c|c|c|c|}
\hline \multirow[b]{3}{*}{$\begin{array}{l}\text { Strain } \\
\text { (lesion) }\end{array}$} & \multicolumn{4}{|c|}{ Substrate } \\
\hline & \multicolumn{2}{|c|}{ Cytosine } & \multicolumn{2}{|c|}{ Uracil } \\
\hline & $\begin{array}{l}K_{\mathrm{m}} \\
(\mu \mathrm{M}) \\
\pm \mathrm{SD}\end{array}$ & $\begin{array}{c}V \text { [pmol } \\
(\mu 1 \text { cell water })^{-1} \\
\left.\mathrm{~s}^{-1}\right] \pm \mathrm{SD}\end{array}$ & $\begin{array}{l}K_{\mathrm{m}} \\
(\mu \mathrm{M}) \\
\pm \mathrm{SD}\end{array}$ & $\begin{array}{c}V[\mathrm{pmol} \\
(\mu \mathrm{l} \text { cell water) })^{-1} \\
\left.\mathrm{~s}^{-1}\right] \pm \mathrm{SD}\end{array}$ \\
\hline $\begin{array}{l}4 \\
\text { (wild-type) }\end{array}$ & $\begin{array}{l}\text { high aff.: } 0 \cdot 8 \pm 0 \cdot 1 \\
\text { low aff.: } 240 \pm 35\end{array}$ & $\begin{array}{c}39 \cdot 7 \pm 4 \cdot 2 \\
770 \pm 170\end{array}$ & $114 \pm 15$ & $7 \cdot 2 \pm 0 \cdot 9$ \\
\hline $\begin{array}{l}\text { cp1 } \\
\text { (cytosine } \\
\text { permease) }\end{array}$ & high aff.: ND & ND & $104 \pm 12$ & $6 \cdot 8 \pm 0.7$ \\
\hline $\begin{array}{l}\text { upl } \\
\text { (uracil } \\
\text { permease) }\end{array}$ & $\begin{array}{ll}\text { high aff.: } & 0 \cdot 9 \pm 0 \cdot 1 \\
\text { low aff.: } & 244 \pm 28\end{array}$ & $\begin{array}{c}41 \cdot 3 \pm 4 \cdot 5 \\
764 \pm 127\end{array}$ & ND & ND \\
\hline $\begin{array}{l}\text { upy0 } \\
\text { (UMP pyro- } \\
\text { phosphorylase) }\end{array}$ & $\begin{array}{ll}\text { high aff.: } & 0 \cdot 8 \pm 0 \cdot 1 \\
\text { low aff.: } & 259 \pm 38\end{array}$ & $\begin{array}{r}38 \cdot 5 \pm 3 \cdot 9 \\
747 \pm 111\end{array}$ & $119 \pm 18$ & $7 \cdot 0 \pm 0.8$ \\
\hline $\begin{array}{l}\text { cd3 } \\
\text { (cytosine } \\
\text { deaminase) }\end{array}$ & $\begin{array}{ll}\text { high aff: : } & 0 \cdot 8 \pm 0 \cdot 2 \\
\text { low aff.: } & 247 \pm 22\end{array}$ & $\begin{array}{c}35 \cdot 3 \pm 4 \cdot 0 \\
738 \pm 101\end{array}$ & $107 \pm 13$ & $7 \cdot 5 \pm 1 \cdot 1$ \\
\hline
\end{tabular}

permease-deficient strains, were within experimental error identical to those obtained for the parental strain 4 (Table 4). There was no detectable transport of uracil into the uracil-permease-deficient strain of C. glabrata. Transport of these substrates is functionally separated from their intracellular metabolism. This conclusion was true also for the other pyrimidines tested as in cells incubated with radiolabelled pyrimidines radioactivity appeared intracellularly first as the free pyrimidine and after a short lag period radiolabelled phosphorylated derivatives appeared.

Analysis of the data revealed that transport of all pyrimidines tested in C. glabrata strain 4 and C. albicans strain $72 \mathrm{~S}$ was mediated by saturable processes, obeying Michaelis-Menten kinetics. The apparent $K_{\mathrm{m}}$ and $V$ values differed for different pyrimidines, which suggested that these substrates may not share a common permease(s). The values for $K_{\mathrm{m}}$ and $V$ differ from the published data but such differences could reflect the different techniques used and, in particular, differences in the incubation temperature and the $\mathrm{pH}$ value of the suspending medium, since it has been shown that in $S$. cerevisiae the experimentally determined values of $K_{\mathrm{m}}$ are dependent upon pH (Foret et al., 1978).

Relationship between intracellular and extracellular concentrations of pyrimidines and pyrimidine nucleosides

The ratio of the intracellular and extracellular concentrations of pyrimidines at steady state gives an indication of whether an active or passive mechanism of transport is operating to accumulate these substances within the cell. In $C$. albicans and $C$. glabrata, all pyrimidines tested reached their steady-state intracellular concentration $\left(S_{\mathrm{i}}\right)$ after $5 \mathrm{~min}$ incubation with the radiolabelled substrate. Since in C. glabrata cytosine enters the cell by two transport systems, the steady-state intracellular concentration of cytosine $\left(S_{\mathrm{i}}\right)$ was measured as a function of the cytosine concentration in the medium $\left(S_{0}\right)$ (Fig. 2). These measurements were made in C. glabrata strain cd 3 which

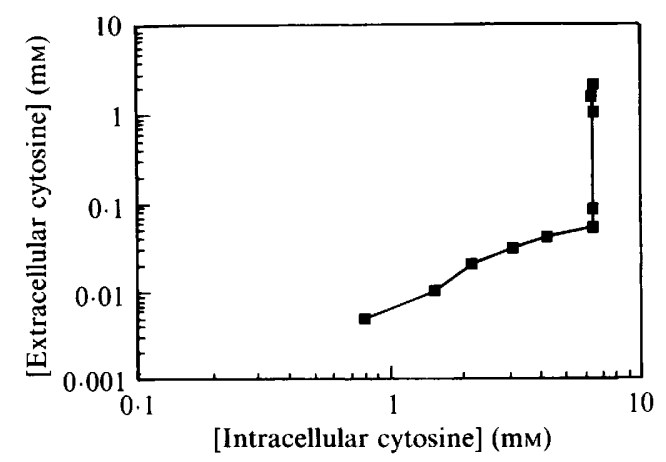

Fig. 2. Intracellular concentration of cytosine in C. glabrata strain cd3 as a function of the concentration of cytosine in the medium. Cells $(5 \times$ $10^{7}$ ) were incubated for $5 \mathrm{~min}$ with different concentrations of $\left[{ }^{14} \mathrm{C}\right]$ cytosine. Following centrifugation through oil into $0 \cdot 2 \mathrm{M}$-TCA, cell-associated radioactivity was measured. All the radioactivity detected was in the form of cytosine, as determined chromatographically. 
is totally defective in cytosine deaminase, to avoid the problem of artefacts caused by rapid intracellular metabolism of cytosine. In C. glabrata, the steady-state ratio $S_{\mathrm{i}} / S_{0}$ for cytosine (Fig. 2) was high at low external concentrations of cytosine and decreased when $S_{0}$ exceeded $50 \mu \mathrm{M}$. This indicated that the high affinity transport system operated by means of a concentrative (active) mechanism whereas the low affinity system did not. More accurate data are required to determine the relative importance of passive and facilitated diffusion in cytosine transport in $C$. glabrata when cytosine is present in high concentrations in the medium.

The steady-state ratios $S_{\mathrm{i}} / S_{0}$ for all pyrimidines and pyrimidine nucleosides tested in both $C$. albicans and $C$. glabrata, measured at a fixed external concentration of $50 \mu \mathrm{M}$ are given in Tables 2 and 3. With the exception of cytosine, where the $S_{\mathrm{i}} / S_{0}$ ratio was determined in a strain unable to metabolize cytosine, the $S_{\mathrm{i}} / S_{0}$ values for the other compounds will not be an accurate estimation of the concentrative powers of the respective transport systems since, at the time of measurement, a significant amount of the pyrimidine had already been converted into phosphorylated derivatives. In both C. albicans and C. glabrata cytosine transport was the most efficient with $S_{\mathrm{i}} / S_{0}$ values of 106 and 120 respectively, whilst uracil transport was the least efficient, with $S_{\mathrm{i}} S_{0}$ values of 4.4 and 3.6 respectively. These results are in agreement with those of other workers (Lossan et al., 1987; Reichert \& Foret, 1977; Hopkins et al., 1988) and support the finding that pyrimidine transport is energetically coupled to a proton symport. This conclusion was further substantiated by the observation that pre-incubation of cells with glucose was necessary to obtain significant rates of transport for all pyrimidines and nucleosides tested.

\section{Specificity of pyrimidine and pyrimidine nucleoside trans- port in C. glabrata and C. albicans}

The specificity of transport of pyrimidine bases and nucleosides into $C$. glabrata strain 4 and C. albicans strain $72 \mathrm{~S}$ was assessed by monitoring the effect of preincubating the cultures for $60 \mathrm{~s}$ with unlabelled purines, pyrimidines, their nucleosides and analogues of them (final concn $100 \mu \mathrm{M}$ ) on the subsequent incorporation of ${ }^{14} \mathrm{C}$-labelled pyrimidines and ${ }^{14} \mathrm{C}$-labelled pyrimidine nucleosides (final concn $50 \mu \mathrm{M}$ ). Where there was a reduction in the uptake of the ${ }^{14} \mathrm{C}$-labelled pyrimidine or pyrimidine nucleoside it was assumed that both compounds entered the cell via the same transport system. In both $C$. glabrata and $C$. albicans the transport of individual pyrimidines occurred independently of that of the corresponding nucleosides. In addition, the pyrimidine bases did not share a common transport system, although in $C$. albicans cytosine shared a common transport system with the purines adenine, guanine and hypoxanthine since pre-incubation with these compounds resulted in a $70-80 \%$ reduction in the uptake of cytosine. This was in agreement with results obtained by Polak \& Grenson (1973). In C. glabrata, pre-incubation with these purines had no effect on cytosine transport and presumably they were not transported into this organism by the cytosine permease. It was also clear that the fluorinated pyrimidines shared the same transport system with their unfluorinated counterparts, as the transport of the latter compounds into the cell was completely prevented in the presence of the analogues.

In C. glabrata transport of a pyrimidine nucleoside into the cell was not significantly affected by preincubating the cells for $60 \mathrm{~s}$ in the presence of other nucleosides $(100 \mu \mathrm{M})$, suggesting that in this organism there are separate transport systems for cytidine, thymidine and uridine. In $C$. albicans there was some overlap in the transport systems for the pyrimidine nucleosides. In particular, cytidine and adenosine inhibited the transport of uridine by $69 \%$ and $73 \%$ respectively, indicating a common transporter for the three nucleosides. As thymidine had no effect on the transport of uridine, it would appear that in C. albicans there exists more than one nucleoside transport system, one of which is shared by adenosine, cytidine and uridine.

The specificity of uridine permeases in C. albicans and C. glabrata was further investigated. Firstly, by studying the growth inhibitory effects of other toxic nucleosides on uridine permease deficient strains; secondly, by measuring the uptake of radiolabelled nucleosides into parental and uridine-permease-deficient strains; and thirdly, by assessing the protective effects of selected nucleosides on the toxicity of 5-FUrd. Three uridinepermease-deficient strains were examined; udp1 and udp2 were derived from $C$. glabrata strain 4 and $6 \mathrm{~F} 1$ from $C$. albicans strain $72 \mathrm{~S}$. These strains were resistant to 5 -FUrd at a concentration of $1000 \mu \mathrm{g} \mathrm{ml}^{-1}$ whereas growth of the parental strains was inhibited at concentrations less than $1 \mu \mathrm{g} \mathrm{ml}^{-1}$. These uridine-permeasedeficient strains were sensitive to the toxic effects of 5FC and 5-FU.

Fourteen nucleoside analogues were tested for their growth inhibitory effects on both the parental and the uridine-permease-deficient strains of Candida by examining their ability to produce a zone of inhibition when $100 \mu \mathrm{g}$ of the analogue was applied to the surface of an agar plate seeded with the relevant strain of yeast. 4-Aminopyrazolopyrimidine, bredinin, 5-fluorocytidine, 5-FUrd, purine riboside, sinefungin and tunicamycin all inhibited the growth of $C$. albicans strain $72 \mathrm{~S}$. C. albicans strain $6 \mathrm{~F} 1$, which was 5-FUrd resistant, was also resistant to bredinin, 5-fluorocytidine and purine riboside, but was as sensitive to 4-aminopyrazolopyrimidine, 
sinefungin and tunicamycin as the parental wild-type strain. The uridine-permease-deficient strains of $C$. glabrata, udp1 and udp2, were sensitive to 5-fluorocytidine, a result consistent with the observation that cytidine is not transported into this organism by a uridine permease.

$\left[{ }^{14} \mathrm{C}\right]$ Uridine incorporation into uridine-permeasedeficient strains of both C. albicans and C. glabrata was depressed to values approximately $10 \%$ of those obtained for incorporation into the parental strains. This reduction in uptake was also observed with $\left[{ }^{14} \mathrm{C}\right]$ adenosine for the uridine-permease-defective strain of $C$. albicans but not for those of $C$. glabrata. In C. glabrata adenosine was incorporated very poorly as was thymidine in both $C$. albicans and C. glabrata. As expected in both C. glabrata and $C$. albicans uridine gave good protection against inhibition by 5 -FUrd in liquid culture. In C. glabrata no other nucleoside provided protection whereas in $C$. albicans adenosine counteracted the toxicity of 5-FUrd.

Little is known of the mechanisms and specificity of pyrimidine nucleoside transport systems in Candida, although it appears that the transport step is independent of phosphorylase activity (Rao et al., 1983). The uridine permeases of $C$. albicans and C. glabrata have different substrate specificities. 5-FUrd, uridine, adenosine, bredinin, cytidine, 5-fluorocytidine and purine riboside are substrates for this transport system in C. albicans, whereas in C. glabrata only 5-fluorouridine and uridine are transported via the uridine permease. Also, in addition to being toxic to the parental strains, 4aminopyrazolopyrimidine, sinefungin and tunicamycin in C. albicans, and 4-aminopyrazolopyrimidine, 5fluorocytidine and tunicamycin in C. glabrata, were toxic to strains lacking uridine permease, indicating the presence of alternative routes of nucleoside entry into these organisms. 5-Fluoro-2-deoxyuridine (5-FdUrd) was inactive against both $C$. glabrata strain 4 and $C$. albicans strain $72 \mathrm{~S}$, a surprising result in view of the toxicity of this drug to other eukaryotic cells (Martindale, 1982). There are two main possibilities for this lack of toxicity. Firstly, that 5-FdUrd enters the cells but is not metabolized to toxic nucleotide derivatives, and secondly, that 5-FdUrd cannot enter the cell (data not shown).

Examination of the structures of the nucleosides sharing the uridine transporter in $C$. albicans revealed wide differences in nucleobase structure with an intact sugar moiety as the common structural element between these compounds. The importance of this feature in the specificity requirements of uridine permease was confirmed by the finding that 5-FdUrd, whose only difference from 5 -FUrd is a hydrogen atom replacing a hydroxyl group at position 2 of the sugar ring, is not a substrate for the transporter. Indeed, the presence of an intact hydroxyl group at position 2 of the sugar moiety of a nucleoside may be itself an important structural requirement for substrates of this uridine transporter.

\section{References}

ARNOLD, W. N. (1973). Volume and enzyme content of the periplasmic space in yeast. Physiological Chemistry and Physics 5, 117-123.

Chevallier, M. R., Jund, R. \& Lacroute, F. (1975). Characterization of cytosine permeation in Saccharomyces cerevisiae. Journal of Bacteriology 122, 629-641.

FASOLI, M. O. F. (1989). Pyrimidine transport and salvage metabolism in pathogenic Candida. PhD thesis, University of Cambridge, UK.

FASOLI, M. O. F. \& KERRIDGE, D. (1988). Isolation and characterization of fluoropyrimidine resistant mutants in two Candida species. Annals of the New York Academy of Sciences 544, 260-263.

FORET, M., SCHMIDT, R. \& REICHERT, U. (1978). On the mechanism of substrate binding to the pyrimidine transport system of Saccharomyces cerevisiae. European Journal of Biochemistry 82, 33-43.

Harley, E. R., Paterson, A. R. P. \& Cass, C. E. (1982). Initial rate kinetics of the transport of adenosine 4-amino-7-( $\beta$-D-ribofuranosyl) pyrrolo[2-3-d]pyridine, Tubericidin in cultured cells. Cancer $R e^{-}$ search 42, 1289-1295.

Hopkins, P., Chevallier, M. R., Jund, R. \& EdDy, A. A. (1988). Use of plasmid vectors to show that uracil and cytosine permeases of the yeast Saccharomyces cerevisiae are electrogenic proton symports. FEMS Microbiology Letters 49, 173-177.

Jund, R., Chevallier, M. R. \& LaCroute, F. (1977). Uracil transport in Saccharomyces cerevisiae. Journal of Membrane Biology 36, 233 251.

Lossan, R., Jund, R. \& Chevallier, M. R. (1978). Properties of three distinct pyrimidine transport systems in yeast. Evidence for distinct energy coupling. Biochimica et Biophysica Acta 513, 296-300.

MarTindale (1982). The General Pharmacopoeia, 28th edn. Edited by J. E. F. Reynolds. London: Pharmaceutical Press.

Polak, A. \& Grenson, M. (1973). Evidence for a common transport system for cytosine, adenine and hypoxanthine in Saccharomyces cerevisiae and Candida albicans. European Journal of Biochemistry 32, $276-282$.

RaO, T. V. G., Verna, R. S. \& Prasad, R. (1983). Transport of purines, pyrimidine bases and nucleosides in Candida albicans a pathogenic yeast. Biochemistry International 6, 409-417.

REICHERT, V. \& FORET, M. (1977). Energy coupling in hypoxanthine transport in yeast. Potentiometric evidence for proton symport and potassium antiport. FEBS Letters 83, 325-328.

Scherrer, R., Louden, L. \& Gerhardt, P. (1974). Porosity of the yeast cell wall and membrane. Journal of Bacteriology 118, 534-540.

WHELAN, W. L. \& KERRIDGE, D. (1984). Decreased activity of UMP : pyrophosphorylase associated with resistance to 5-fluorocytosine in Candida albicans. Antimicrobial Agents and Chemotherapy 26, $570-574$.

Whelan, W. L., Simon, S., Beneke, E. S. \& Rogers, A. L. (1984). Auxotrophic mutants of Torulopsis glabrata. FEMS Microbiology Letters 24, 1-4.

Wohlhueter, R. M., Marz, R., Graft, J. C. \& Plagemann, P. G. W. (1978). A rapid-mixing technique to measure transport in suspended animal cells. Applications to nucleoside transport in Novikoff rat hepatoma cells. Methods in Cell Biology 20, 211-236. 